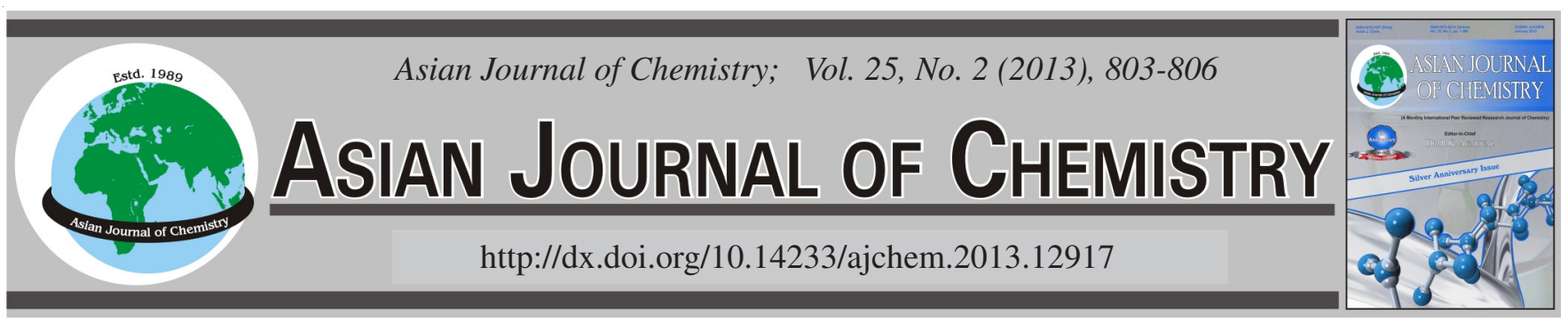

\title{
Comparative Analysis of Volatile Oils from Lonicera japonica Thunb. var. chinensis wakey by HS-SPME and GC-MS
}

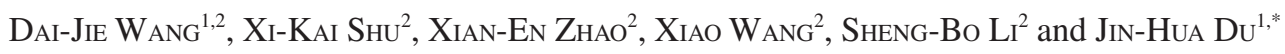

${ }^{1}$ College of Food Science and Engineering, Shandong Agricultural University, 61 Daizong Street, Taian 271018, P.R. China

${ }^{2}$ Shandong Analysis and Test Center, Shandong Academy of Sciences, 19 Keyuan Street, Jinan 250014, P.R. China

*Corresponding author: Tel: +86538 8249157; E-mail: djh@sdau.edu.cn

\begin{abstract}
The volatile oils of the flowering stages, i.e., the flower bud stage, silver flowering stage, gold flowering stage as well as the leaf from Lonicera japonica Thunb. var. chinensis wakey were extracted and analyzed by headspace solid-phase microextraction and GC-MS. In this study, Lonicera japonica Thunb. was used as contrastive species. The fiber coating of $65 \mu \mathrm{m}$ PDMS/DVB was chosen to extract the volatile oils. A total of 46, 50, 51 and 20 volatile compounds were identified, constituting of 98.16, 97.31, 95.99 and $97.84 \%$ of oil composition of the flower bud stage, silver flowering stage, gold flowering stage and leaf from L. japonica var. chinensis wakey, respectively. The dominant constituents of the above parts were hydrocarbons (37.79\%), oxygenated monoterpenes (28.98 \%), alcohols (25.44 \%) and esters $(53.29 \%)$. It is concluded that the esters in flowering period contributed to the attractive aroma of L. japonica var. chinensis wakey.
\end{abstract}

Key Words: Lonicera japonica Thunb. var. chinensis wakey, Volatile oils, Analysis, Comparison, HS-SPME-GC-MS.

\section{INTRODUCTION}

Lonicera japonica Thunb. (Jin Yin Hua or Ren Dong in Chinese, Caprifoliaceae plants) is one of the most common traditional Chinese medicines and used for treating various diseases, including arthritis, diabetes mellitus, fever, infections, sores and swelling ${ }^{1}$. Pharmacological studies indicated that their extracts have a broad spectrum of biological activities, such as antibacterial, antiinflammatory, antioxidant, antipyretic, antiviral and hepato-protective effects ${ }^{2-6}$. It is sprawling and twining lianas; young stems pubescent; leaves ovate, elliptic, oblong or broadly lanceolate, branch of the year and blade common green. The flowering period can be divided into three stages, i.e., the flower bud stage, the silver flowering stage and the gold flowering stage $\mathrm{e}^{7}$. Now as an ornamental groundcover, L. japonica is commonly planted in many areas for sprawling habit, numerous sweetly fragrant white flowers and attractive evergreen foliage, becoming naturalized in Argentina, Brazil, Mexico, Australia, New Zealand and United States.

L. japonica var. chinensis wakey, growing quickly and adaptable, with purple, essentially glabrous leaves, red flowers and attractive aroma, is a mutation of L. japonica. The aroma of L. japonica var. chinensis wakey is more fragrant and attractive than L. japonica. It is a good ornamental and medicinal plant.
Headspace solid-phase microextraction (HS-SPME) is a solvent free sampling technique first introduced by Pawliszyn and co-workers ${ }^{8}$. At present, HS-SPME has been widely used in environmental, biological and food analysis for its simplicity, speed and sensitivity ${ }^{9,10}$. HS-SPME combined with GC/MS analysis has being a suitable technique for the analysis of volatile oils in many fields ${ }^{11-13}$.

To our best of knowledge, there is no report about the chemical analysis of the volatile oils from L. japonica var. chinensis wakey in literature. The aim of this paper is to systematically compare the volatile oils of $L$. japonica var. chinensis wakey with those of L. japonica in the flowering stages, i.e., the flower bud stage, silver flowering stage, gold flowering stage as well as the leaf, for the clear understanding of this plant.

\section{EXPERIMENTAL}

The fresh materials of L. japonica var. chinensis wakey "Yatehong" and L. japonica "Yate" were collected in May 2011 from Shandong Analysis and test center. The species were authenticated by Pro. Fa-zeng LI (College of Life Science, Shandong Normal University, Jinan, China).

GC-MS was performed with an Agilent 6890N-5973N; Capillary column HP-5MS ( $30 \mathrm{~m} \times 0.25 \mathrm{~mm}, 0.25 \mu \mathrm{m})$ quartz capillarity columniation. The following SPME fibers (Supelco, Bellefonte, PA, USA) were used for the extraction procedure: $65 \mu \mathrm{m}$ PDMS/DVB, $70 \mu \mathrm{m}$ CW/DVB and $100 \mu \mathrm{m}$ PDMS. 
Preparation of samples and extraction of volatile oils: The sample preparation for solid-phase microextraction was as follows: $3 \mathrm{~g}$ of sample was cut into pieces and instantly introduced into a $15 \mathrm{~mL}$ headspace vial. The solid-phase microextraction device was inserted in the sealed vial containing the sample prepared as described above and the fiber was exposed to the sample headspace for $0.5 \mathrm{~h}$ in a water bath $\left(30^{\circ} \mathrm{C}\right)$. The following solid-phase microextraction fibers (Supelco, Bellefonte, PA, USA) were used for the extraction procedure: $65 \mu \mathrm{m}$ PDMS/DVB, $70 \mu \mathrm{m}$ CW/DVB and $100 \mu \mathrm{m}$ PDMS.

Conditions of the GC-MS analysis: The capillary GC analysis was conducted using an Agilent $6890 \mathrm{~N}$ gas chromatograph system (Agilent Technologies). The temperature program used for analysis was as follows: (1) isothermal temperature at $50^{\circ} \mathrm{C}$ for $2 \mathrm{~min}$; (2) heating from $50-120^{\circ} \mathrm{C}$ at a rate of $2{ }^{\circ} \mathrm{C} / \mathrm{min}$; (3) isothermal processing at $120^{\circ} \mathrm{C}$ for $5 \mathrm{~min}$; (4) heating from $120-160^{\circ} \mathrm{C}$ at a rate of $5^{\circ} \mathrm{C} / \mathrm{min}$; (5) isothermal processing at $160^{\circ} \mathrm{C}$ for $10 \mathrm{~min}$; (6) heating from $160-240{ }^{\circ} \mathrm{C}$ at a rate of $10^{\circ} \mathrm{C} / \mathrm{min}$; (7) isothermal processing at $240^{\circ} \mathrm{C}$ for $5 \mathrm{~min}$. Helium $(99.999 \%)$ was used as the carrier gas at a flow-rate of $1 \mathrm{~mL} / \mathrm{min}$. The injector temperature was set at $240{ }^{\circ} \mathrm{C}$ and desorption was performed at the injector for $3 \mathrm{~min}$. The injection was performed in the splitless model. For identification, the electron impact ionization conditions were as follows: ion energy $70 \mathrm{eV}$ and the mass range scanned was 30-500 amu in the full scan acquisition mode.

Identification of constituents: Retention indices of all the components were determined by Kovats method using $n$ alkanes $\left(\mathrm{C}_{6}-\mathrm{C}_{30}\right)$ as standards (Supelco, Bellefonte, PA, USA). The constituents of the volatiles were identified by the Wiley 138, NIST 02 and HPCH 1607 (Allured Corp., Carol Stream, IL) libraries and with data published in the literatures ${ }^{14-16}$.

\section{RESULTS AND DISCUSSION}

SPME fiber selection: Three fiber coatings, i.e., $65 \mu \mathrm{m}$ PDMS/DVB, $70 \mu \mathrm{m}$ CW/DVB and $100 \mu \mathrm{m}$ PDMS were used to test the volatile oils present in the flower bud stage of $L$. japonica var. chinensis wakey. Fig. 1 showed the chromatograms obtained using these three fibers. The $65 \mu \mathrm{m}$ PDMS/ DVB fiber coating was chosen for the further study considering its better performance in extracting more variety of compounds and larger amount.

Analysis of samples: The GC-MS analysis of the volatile oils from the flower bud, silver flower, gold flower and leaf of L. japonica var. chinensis wakey and L. japonica are presented in Table-1. Altogether, 57 volatile compounds were identified by GC-MS with HP-5MS column.

The flower bud volatile oils were revealed the presence of 46 and 45 components, representing 98.16 and $97.87 \%$ of the total oils in $L$. japonica var. chinensis wakey and $L$. japonica. The major compounds in the flower bud volatile oils of L. japonica var. chinensis wakey were 1-allyl-2-methylcyclopentane (37.79\%), cis-3-hexenyl-2- methylbutyrate $(7.85 \%)$ and linalool $(7.01 \%)$, while in L. japonica they were linalool (40.36\%), 1-allyl-2-methylcyclopentane (19.72\%) and $\delta$-cadinene $(3.80 \%)$. A total of 50 and 47 components were identified at the silver flowering stage with linalool $(28.88 \%)$,

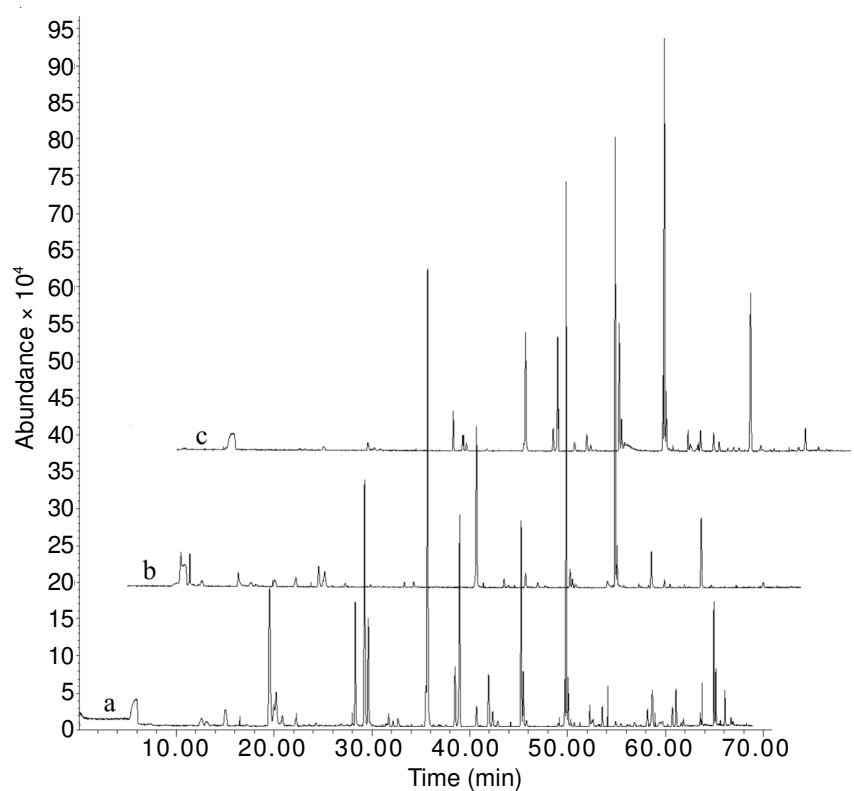

Fig. 1. GC-MS chromatograms of the comparison three fiber coatings used for SPME (a) $65 \mu \mathrm{m}$ PDMS/DVB; (b) $70 \mu \mathrm{m}$ CW/DVB; (c) $100 \mu \mathrm{m}$ PDMS)

1-allyl-2-methylcyclopentane (19.49\%) and (Z)-3-hexen-1$\mathrm{ol}(6.77 \%)$ as the major compounds in the volatile oils of $L$. japonica var. chinensis wakey and linalool (36.57\%), 1-allyl2-methylcyclopentane $(10.43 \%)$ and (E)-germacrene D (7.65 $\%)$ as major compounds in L. japonica. A total of 51 and 47 components were identified, respectively in $L$. japonica var. chinensis wakey and L. japonica at the gold flowering stage. The main compounds at this stage in L. japonica var. chinensis wakey were linalool (23.58 \%), (Z)-3-hexen-1-ol (16.19\%) and 1-allyl-2-methylcyclopentane (13.61\%). Comparatively, they are linalool (33.95\%), 1-allyl-2-methylcyclopentane $(11.06 \%)$ and (E)-germacrene D (8.01\%) in L. japonica. Twenty components accounting for 97.84 and $98.44 \%$ of constituents of the leaf volatile oils from L. japonica var. chinensis wakey and $L$. japonica were identified. The major compounds were (Z)-3-hexen-1-ol, acetate (27.28\%), (Z)-3-hexen-1-ol (23.39\%) and (E)-2-hexen-1-ol, acetate (13.07\%) in L. japonica var. chinensis wakey and (Z)-3-hexen-1-ol (64.98\%), 1-hexanol $(17.76 \%)$ and acetic acid, hexyl ester $(3.55 \%)$ in L. japonica.

The volatile compounds were separated into eight chemical classes and the chemical distribution of the volatile oils was summarized in Table-2. The dominant constituents of the flower bud volatile oils were hydrocarbons $(37.79 \%)$ and esters $(30.04 \%)$ in L. japonica var. chinensis wakey, while oxygenated monoterpenes $(40.47 \%)$ and hydrocarbons (19.72 $\%)$ featured in $L$. japonica. The oxygenated monoterpenes (28.9\% in L. japonica var. chinensis wakey and $21.20 \%$ in $L$. japonica) and sesquiterpene hydrocarbons (36.61\% in $L$. japonica var. chinensis wakey and $32.48 \%$ in L. japonica) were the major constituents of the silver flowering stage. Eight esters and five alcohols were identified in the leaf volatile oils from L. japonica var. chinensis wakey which contributed to 53.29 and $37.67 \%$ of total oils. Nine esters and four alcohols indentified in leaf volatile oils from $L$. japonica accounted for 13.33 and $83.59 \%$ of total oils. Apparently, terpenoids in leaf were fewer compared with flowers. 
TABLE-1

VOLATILE OILS CONSTITUENTS OF L. japonica var. chinensis wakey (A) AND L. japonica (B) ${ }^{\mathrm{a}}$

\begin{tabular}{|c|c|c|c|c|c|c|c|c|c|}
\hline \multirow{3}{*}{ RI } & \multirow{3}{*}{ Compounds } & \multicolumn{8}{|c|}{ Area $(\%)$} \\
\hline & & \multicolumn{2}{|c|}{ Flower bud } & \multicolumn{2}{|c|}{ Silver flower } & \multicolumn{2}{|c|}{ Gold flower } & \multicolumn{2}{|c|}{ Leaf } \\
\hline & & $\mathrm{A}$ & $\mathrm{B}$ & $\mathrm{A}$ & $\mathrm{B}$ & A & $\mathrm{B}$ & A & $\mathrm{B}$ \\
\hline 825 & 2-Methyl-1-butanol & 0.70 & 0.49 & 0.61 & 0.17 & 0.44 & 0.25 & - & - \\
\hline 850 & 2-Methyl-butanoic acid, methyl ester & 0.29 & - & 0.28 & - & 0.21 & - & - & - \\
\hline 902 & (E)-2-Butenoic acid, ethyl ester & 0.09 & 0.93 & 0.09 & - & - & - & - & - \\
\hline 905 & 2-Methyl butanoic acid, ethyl ester & 0.26 & 0.51 & 0.35 & 0.02 & 0.15 & - & - & - \\
\hline 910 & (Z)-3-hexen-1-ol & 3.72 & 3.10 & 6.77 & 3.64 & 16.19 & 4.82 & 23.39 & 64.98 \\
\hline 915 & Anti-2-methyl-butyl aldoxime & 0.88 & 0.82 & 0.59 & 0.45 & 0.40 & 0.60 & - & - \\
\hline 917 & 1-Hexanol & - & - & - & - & - & - & 11.97 & 17.76 \\
\hline 918 & 2-Methylene-butanoic acid, methyl ester & 1.34 & 0.53 & 1.64 & 0.38 & 2.75 & 0.61 & - & - \\
\hline 940 & 2-Heptanol & 0.98 & 0.62 & 0.37 & 0.22 & 0.61 & 0.46 & 0.77 & 0.45 \\
\hline 955 & 1,4-Hexadiene & - & - & - & - & - & - & 0.43 & 0.14 \\
\hline 969 & Ethyl tiglate & 0.39 & 0.67 & 1.27 & 0.07 & 0.71 & 0.10 & - & - \\
\hline 998 & 1-Octen-3-ol & - & - & - & - & - & - & 0.66 & 0.40 \\
\hline 1007 & dl-6-Methyl-5-hepten-2-ol & 2.20 & 0.97 & 1.06 & 0.52 & 3.32 & 0.74 & - & - \\
\hline 1010 & 3-Octanol & 0.14 & - & 0.16 & - & 0.32 & 0.12 & 0.88 & - \\
\hline 1012 & Hexanoic acid, ethyl ester & - & & - & & & & - & 0.52 \\
\hline 1018 & (Z)-3-Hexen-1-ol, acetate & 1.79 & 2.58 & 1.46 & 2.93 & 4.89 & 3.55 & 27.28 & 4.20 \\
\hline 1022 & Acetic acid, hexyl ester & 1.52 & 1.41 & 0.31 & 0.74 & 0.99 & 1.00 & 10.96 & 3.55 \\
\hline 1024 & (E)-2-hexen-1-ol, acetate & - & - & - & - & - & - & 13.07 & 0.45 \\
\hline 1038 & Limonene & - & 0.18 & 0.11 & 0.11 & 0.06 & 0.07 & - & - \\
\hline 1045 & 2-Ethyl-hexanoic acid, methyl ester & 0.52 & - & 0.11 & - & 0.23 & - & - & - \\
\hline 1050 & (Z)-3,7-Dimethyl-1,3,6-Octatriene & 0.71 & 0.82 & 0.42 & 0.26 & 0.29 & 0.23 & 4.79 & 0.13 \\
\hline 1056 & 3-Octen-1-ol & - & - & - & 0.22 & 4.26 & 0.59 & - & - \\
\hline 1071 & (Z)-Linalool oxide (furanoid) & 0.41 & 0.11 & 0.10 & 0.03 & 0.19 & 0.11 & - & - \\
\hline 1088 & (Z)-3-Hexen-1-ol, propanoate & 0.22 & - & 0.56 & - & 1.62 & - & 0.39 & 0.83 \\
\hline 1090 & Linalool & 7.01 & 40.36 & 28.88 & 36.57 & 23.58 & 33.95 & - & - \\
\hline 1112 & Terpinolene & - & 0.06 & 0.04 & 0.05 & 0.23 & 0.04 & - & - \\
\hline 1123 & cis-3-hexenyl isobutyrate & 1.30 & 0.81 & 1.33 & 0.48 & 1.02 & 0.49 & 0.29 & 0.69 \\
\hline 1150 & Butanoic acid, (Z)-3-hexenyl ester & 0.41 & 0.51 & 1.34 & 0.37 & 0.88 & 0.41 & - & - \\
\hline 1155 & Benzoic acid, ethyl ester & - & 0.85 & 0.33 & 1.15 & 0.19 & 0.96 & - & - \\
\hline 1166 & Butanoic acid, (E)-3-hexenyl ester & 3.29 & 0.30 & 0.67 & 0.27 & 0.38 & 0.20 & 0.79 & 1.41 \\
\hline 1171 & Isobutyric acid, hexyl ester & 1.24 & 0.13 & 0.12 & 0.03 & 0.07 & 0.05 & - & - \\
\hline 1176 & (Z)-3-Octen-1-ol, acetate & - & 0.12 & 0.33 & 0.19 & 0.71 & 0.33 & - & - \\
\hline 1209 & Cis-3-hexenyl-2-methylbutyrate & 7.85 & 1.64 & 1.94 & 0.55 & 1.61 & 0.61 & 0.40 & 1.48 \\
\hline 1212 & 2-Butenoic acid, (E,Z)-3-hexenyl ester & 2.77 & 1.85 & 1.76 & 0.62 & 1.32 & 0.59 & - & - \\
\hline 1217 & 2-Butenoic acid, hexyl ester & 0.35 & 0.29 & 0.33 & 0.10 & 0.22 & 0.15 & - & - \\
\hline 1229 & 2,7-Dimethyl-2,6-octadien-1-ol & - & - & - & 0.02 & 0.31 & 0.06 & - & - \\
\hline 1279 & 1-Allyl-2-methylcyclopentane & 37.79 & 19.72 & 19.49 & 10.43 & 13.61 & 11.06 & 0.86 & 0.80 \\
\hline 1282 & Tiglic acid, isobutyl ester & 6.16 & 1.70 & 1.49 & 0.49 & 0.82 & 0.45 & - & - \\
\hline 1286 & (-)-Isocaryophyllene & 0.45 & 0.41 & 0.48 & 0.66 & 0.34 & 0.61 & - & - \\
\hline 1300 & $\alpha$-Cubebene & 0.25 & 0.31 & 0.47 & 0.64 & 0.27 & 0.59 & - & - \\
\hline 1316 & (Z)-3-Hexen-1-yl hexanoate & 0.24 & - & 0.20 & 0.11 & 0.18 & 0.07 & 0.10 & 0.20 \\
\hline 1322 & Copaene & 0.60 & 0.50 & 0.65 & 0.94 & 0.47 & 0.97 & - & - \\
\hline 1338 & cis-Jasmone & 0.65 & 0.33 & 1.58 & 1.42 & 1.10 & 1.17 & - & - \\
\hline 1359 & (+)-Calarene & 0.41 & 0.44 & 0.93 & 1.80 & 0.52 & 1.75 & - & - \\
\hline 1369 & $\beta$-Cubebene & 0.29 & 0.33 & 0.60 & 1.09 & 0.33 & 1.07 & - & - \\
\hline 1380 & (-)-Alloaromadendren & 0.13 & 0.14 & 0.43 & 0.36 & 0.28 & 0.37 & - & - \\
\hline 1393 & $(-)$-Cloven & 0.24 & 0.15 & 0.28 & 0.64 & 0.14 & 0.65 & - & - \\
\hline 1405 & (+)-Epi-bicyclosesquiphellandrene & 0.13 & 0.14 & 0.28 & 0.45 & 0.15 & 0.41 & - & - \\
\hline 1428 & $\alpha$-Amorphene & 1.36 & 2.15 & 2.46 & 3.63 & 1.31 & 3.27 & 0.10 & 0.08 \\
\hline 1444 & (E)-Germacrene D & 2.73 & 2.1 & 3.68 & 7.65 & 2.15 & 8.01 & - & - \\
\hline 1469 & (+)-Calarene & 0.77 & 1.05 & 1.40 & 2.16 & 0.73 & 1.98 & - & - \\
\hline 1480 & $\alpha$-Muurolene & 0.78 & 0.69 & 1.22 & 1.27 & 0.69 & 1.15 & 0.29 & 0.08 \\
\hline 1497 & $\beta$-Cadinene & 0.13 & 0.26 & 0.40 & 0.64 & 0.19 & 0.56 & - & - \\
\hline 1517 & $\gamma$-Muurolene & 1.37 & 2.11 & 2.41 & 3.31 & 1.40 & 2.91 & 0.16 & 0.08 \\
\hline 1531 & $\delta$-Cadinene & 2.70 & 3.80 & 4.36 & 5.66 & 2.53 & 5.03 & 0.27 & 0.23 \\
\hline 1556 & 1,4-Cadinadiene & 0.15 & 0.23 & 0.34 & 0.43 & 0.17 & 0.39 & - & - \\
\hline 1565 & Naphthalene, $1,2,4 \mathrm{a}, 5,6,8 \mathrm{a}-$ & 0.43 & 0.64 & 0.81 & 1.13 & 0.45 & 1.01 & - & - \\
\hline
\end{tabular}

${ }^{a} \mathrm{RI}$ calculated from retention times relative to that of $n$-alkanes $\left(\mathrm{C}_{6}-\mathrm{C}_{30}\right)$ on the non-polar HP-5MS column. 
TABLE-2

CHEMICAL DISTRIBUTION IN THE VOLATILE OILS OF L. japonica var. chinensis wakey (A) AND L. japonica (B)

\begin{tabular}{|c|c|c|c|c|c|c|c|c|}
\hline \multirow{3}{*}{ Constituents } & \multicolumn{8}{|c|}{ Area (\%) } \\
\hline & \multicolumn{2}{|c|}{ Flower bud } & \multicolumn{2}{|c|}{ Silver flower } & \multicolumn{2}{|c|}{ Gold flower } & \multicolumn{2}{|c|}{ Leaf } \\
\hline & $\mathrm{A}$ & $\mathrm{B}$ & $\mathrm{A}$ & B & A & B & A & B \\
\hline Sesquiterpene hydrocarbons & $12.92(17)$ & $15.45(17)$ & $21.20(17)$ & $32.48(17)$ & $12.13(17)$ & $30.72(17)$ & $0.81(4)$ & $0.47(4)$ \\
\hline Oxygenated monoterpenes & $7.42(2)$ & $40.47(2)$ & $28.98(2)$ & $36.61(2)$ & $23.77(2)$ & $34.07(2)$ & - & - \\
\hline Monoterpenes & $0.71(1)$ & $1.06(3)$ & $0.58(3)$ & $0.42(3)$ & $0.57(3)$ & $0.33(3)$ & $4.79(1)$ & $0.13(1)$ \\
\hline Esters & $30.04(18)$ & $14.83(16)$ & $15.91(20)$ & $8.51(16)$ & $18.96(19)$ & $9.59(15)$ & $53.29(8)$ & $13.33(9)$ \\
\hline Alcohols & $7.75(5)$ & $5.18(4)$ & $8.97(5)$ & $4.81(6)$ & $25.44(7)$ & $7.04(7)$ & $37.67(5)$ & $83.59(4)$ \\
\hline Hydrocarbons & $37.79(1)$ & $19.72(1)$ & 19.49 (1) & $10.43(1)$ & 13.61 (1) & $11.06(1)$ & $1.29(2)$ & $0.94(2)$ \\
\hline Ketones & 0.65 (1) & 0.33 (1) & $1.58(1)$ & $1.42(1)$ & $1.10(1)$ & 1.17 (1) & - & - \\
\hline Others & 0.88 (1) & $0.82(1)$ & 0.59 (1) & 0.45 (1) & $0.40(1)$ & 0.60 (1) & - & - \\
\hline
\end{tabular}

Figures in brackets are the number of compounds.

The esters in each flowering period of $L$. japonica var. chinensis wakey were more represented in both numbers $(18$, 20,19 and 16,16, 15 components) and the percentage (30.04, $15.91,18.96$ and $14.83,8.51,9.59 \%$ ) than in the volatile oils of $L$. japonica (Table-2). It could be an explanation that the aroma in L. japonica var. chinensis wakey is much more fragrant than in L. japonica.

\section{ACKNOWLEDGEMENTS}

The authors acknowledged the National Science and Technology Pillar Program during the Twelfth Five-Year Plan Period (2011BAI06B01), the Project for Science and Technology Development of Shandong Province (2009GG10009043) (20100816632) and the special foundation of Taishan Overseas Distinguished experts and scholars.

\section{REFERENCES}

1. Committee of National Pharmacopoeia, Pharmacopoeia of People's Republic of China, Beijing: Chemical Industry Press, p. 205 (2010).
2. Jiangsu New Medical College, Dictionary of Traditional Chinese Medicine, Shanghai: Shanghai Science and Technology Publishing House Press, p. 1403 (1977).

3. A. Rahman and S.C. Kang, Food Chem., 116, 670 (2009).

4. C. Chang, M. Lin, S. Lee, K. Liu, F. Hsu and J. Lin, Antiviral Res., 27, 367 (1995).

5. H. Ko, B. Wei and W. Chiou, J. Ethnopharmacol., 107, 205 (2006).

6. Y. Xu, B.G. Oliverson and D.L. Simmons, J. Ethnopharmacol., 111, 667 (2007).

7. W.L. Wagner, D.R. Herbst and S.H. Sohmer, Manual of the Flowering Plants of Hawaii, Hawaii: University of Hawaii Press, p. 1356 (1999).

8. C.L.A.J. Pawliszyn, Anal. Chem., 62, 2145 (1990).

9. G.A. Mills and V. Walker, J. Chromatogr. A, 902, 267 (2000).

10. S. Ulrich, J. Chromatogr. A, 902, 167 (2000).

11. Y. Meng, V. Pino and J.L. Anderson, Anal. Chem., 81, 7107 (2009).

12. M.F. Barroso, J.P. Noronha, C. Delerue-Matos and M.B.P.P. Oliveira, J. Agric. Food Chem., 59, 5062 (2011).

13. V.D. Bhatt, R.S. Soman, M.A. Miller and G.B. Kasting, Environ. Sci. Technol., 42, 6587 (2008).

14. Y. Wang, X. Xue, F. Zhang, Q. Xu and X. Liang, Mode. Tradit. Chin. Med. Mater. Med., 10, 45 (2008).

15. J. Wang, Z. Ji and W. Kang, Fine Chem., 25, 1075 (2008).

16. Z.Z. Wang, A.Y. Bi, Q. Shang, W. Xiao and J.A. Duan, Chin. Tradit. Herb. Drugs, 39, 672 (2008). 